\title{
Integrated Methodological Framework for Digital Transformation Strategy Building (IMFDS)
}

\author{
Zineb Korachi ${ }^{1}$, Bouchaib Bounabat ${ }^{2}$ \\ ALQUALSADI Team, ADMIR Laboratory \\ ENSIAS/Mohamed V University in Rabat, Rabat, Morocco
}

\begin{abstract}
There is still a conflict among the definitions, frameworks, and formulation of the digital transformation strategy in the literature. Despite extensive research on Digital Transformation Strategies and Digital Transformation Assessment, there is not a clear and global meta-model describing the general concepts and guidelines of the digital transformation to frame and drive a successful digital transformation. Several digital transformation approaches have been presented in the literature, these approaches are focusing on specific cases and specific concepts. The present paper describes the digital transformation and its relationship with IT governance. It presents how IT governance can lead the digital transformation. A literature review has been conducted on the most well-known IT Frameworks (COBIT, ITIL, CMMI) and their structure in order to provide a standard and known framework by practitioners. This paper proposes an Integrated Methodological Framework for Digital Transformation Strategy Building. The proposed framework is called IMFDS, it is based on IT governance elements (Business Strategic Planning, IT Strategic Planning, IT Organizational Structure, IT Reporting, IT Budgeting, IT Investment Decisions, Steering committee, IT Prioritization Process and IT Reaction Capacity). It provides specific guidelines to help organizations formulating, implementing and monitoring their transformation strategies. IMFDS is articulated across 9 blocks (steps) and 34 processes.
\end{abstract}

Keywords-Digital transformation strategy; digital transformation assessment; IT governance; IT framework

\section{INTRODUCTION}

Digital transformation has become a high priority on leadership agendas, with nearly $90 \%$ of business leaders in the U.S and U.K expecting digital technologies to make an increasing strategic contribution to their business in the coming decade [1]. As a result, organizations need to quickly adapt to the digital era in order to gain competitive advantages and offer added-value to their customers, based on a digital transformation strategy [2]. Recent research has contributed to increase our understanding of specific aspects of the digital transformation phenomenon [3]. Researchers highlight the importance of formulating and evaluating a digital transformation strategy, although this field has not been fully investigated [2]. Digital transformation strategy is still an ongoing area of research, which leads to immature literature and inadequate understanding.

However, despite the multiplicity of new technologies and recipes for their implementation, whether in business, public governance and private life, real digital transformation is taking much longer and facing more difficulties than it has been expected [4]. Organizations want to make a digital transformation of their businesses to take advantage of the digital revolution, but most of them do not know from where to start, what standards to adopt, what are the costs, what are the benefits, what are the challenges, what are the opportunities, what are the strategies to follow, what are the right metrics to use, what are the technologies suitable for their business or activity, what is the percentage of success of this digital transformation, there are hundreds of questions that go through the head of organizations' leaders. To answer all these questions and meet the digital transformation challenges organizations need specific guidelines for building their digital transformation strategy. The most cited articles focus on the understanding of specific aspects of the digital transformation phenomenon. Therefore, they do not provide specific guidelines for organizations to formulate, implement, and evaluate digital transformation strategies. While the building blocks of a digital strategy are known, clearly specified guidelines for managers on how to approach digital transformation and implement a well-defined digital transformation strategy are lacking [1].

Digital transformation needs mature and superb IT governance which helps conduct business processes [5]. Companies with matured IT governance are more likely to engage in digital initiatives and have a better starting point for digital transformation [5]. Some works have presented how IT Governance Objectives can drive digital transformation [6]. Several digital transformation strategies have been presented in the literature, each of these strategies is focused on specific cases and specific concepts. The contribution of this paper is to describe: What are the relationship between IT governance and digital transformation? And How IT governance can drive digital transformation? This work presents an Integrated Methodological Framework for building Digital Transformation Strategies. The proposed framework is constructed based on IT governance components. It is a cyberstrategy framework that consists of two integrated systems. The first system is articulated across nine building blocks and it provides organizations specific guidelines for building their digital transformation strategy. The second one provides an evaluation system (KPIs, dashboard, and maturity model) to evaluate the results and progress of the digital transformation and to continually improve the digital transformation strategy.

The paper is structured as follows: the next section explores related works, followed by a section describing the proposed 
solution (IMFDS framework), followed by discussion, conclusion, and suggestions for future research.

\section{LITERATURE REVIEW}

\section{A. Digital Transformation Strategy}

A digital transformation is the use of technology to radically improve performance or reach of organizations $[7,8]$. The digital transformation is an important cornerstone for helping organizations improve their business processes in order to create business values and competitiveness. This transformation will be effective if it is established within the framework of a digital strategy [9].

Several works have studied the digital transformation concepts and concerns, they have studied: digital strategy definitions, characteristics of failed and successful digital strategies [10], standard for IT governance [11], standard for IT service management [12], maturity models [13], The stages of the digital transformation [14], the challenges of digital transformation [14], areas of focus for the digital transformation[14], Steering committee [14,9], IT Opportunities [14], digital transformation priorities [14], digital strategy in a specific domain [15], digital strategy assessment [16], and digital strategies for building smart cities [16, 17]. Despite the prior research, specific guidelines for organizations on how to build and evaluate digital transformation strategies are still not clear, and both academics and practitioners need to further investigate this field [2].

Researchers tried to find out a process that supports business goals and business strategy, through the development of Information Systems [18]. An in-depth study of literature about digital transformation strategy has been conducted, the most cited articles focus on understanding the digital transformation definitions, concepts, dimensions, phases, and components. Therefore, they do not propose an integrative framework that provides clear guidelines for building and monitoring digital transformation strategies.

\section{B. Digital Transformation Assessment}

The transformation strategy should be revisited and evaluated on a regular basis and make sure that the action plan for implementing the strategy is on the right track [17]. To stay competitive as an organization, there is a need for having a continual process of improvement that scrutinizes the company's positioning in terms of its IT capabilities and the quality of its properties and services [19]. For digital transformation assessment and monitoring, there are several evaluation systems and maturity models in the literature, and each of them deals with a specific problem. For example; The World Health Organization and International Telecommunication Union suggested the use of KPIs (Key Performance Indicators) and Dashboards for evaluating the progress of the eHealth strategy [15].

Appropriate Key Performance Indicators are required in order to assess the contribution that the digital transformation is making toward the organization, but for efficient use and analysis of these metrics, organizations need to exploit them within an evaluation system that provides the ability to analyze and generate information from these metrics. For example; MMDSA (Maturity Model for Digital Strategy Assessment) is a maturity model using KPIs to monitor the progress of the digital strategy [9]. In the literature, there are also some evaluation systems for evaluating the digital transformation of a city $[20,16]$. For example, there is a smart city evaluation system that is articulated across 4 components: Key Performance Indicators, Ranking System, Control system, and Dashboard [16]. The same components can be used to develop a system for assessing the digital transformation strategy.

\section{IT Governance, IT frameworks, and Digital Transformation}

IT governance is an integral part of corporate governance exercised by the board and addresses the definition and implementation of processes, structures and relational mechanisms in the organization that enable both business and IT people to execute their responsibilities in support of business/IT alignment and the creation of business value from IT-enabled business investments [6]. Many sources identify five areas or domains of attention in the context of IT governance that need to be addressed [6, 21]: Strategic alignment, Value delivery, Risk management, Resource management, and Performance measurement. These five areas are the concerns of the digital transformation. For this reason, the adoption of IT governance can drive digital transformation and resolve their concerns.

Strategy and strategic plan should be conceptual, visionary and directional, and should be different from the operational plan [22]. A literature review has been conducted on IT governance, IT management, and IT frameworks in order to take advantage of their structure, components, and limitations to propose a clear and simple integrated methodological framework for digital transformation strategy building.

On the market, there are several tools and frameworks for IT management and governance in fashion such as COBIT (Control Objectives for Business \& Related Technology), ITIL (Information Technology Infrastructure Library), CMMI (Capability Maturity Model Integration), EFQM (European Foundation for Quality Management), BSC (Balanced Scorecard), Ect. Using these frameworks independently prevents organizations from achieving the full benefits of IT Governance because every practice has its limitations on its application to specific IT areas and all these practices overlap $[23,24]$. For example, the important thing about ITSM and therefore ITIL or COBIT is to improve the quality of IT services [11]. To see if it is achieved, the quality should be measured. But neither COBIT nor ITIL measures the quality, so it is necessary to use other methodologies [11]. EFQM is proposed for this purpose because it is the best methodology to measure the quality [25]. ITIL provides the how for service management aspects, COBIT helps to define what should be done and EFQM defines and measures the how of quality improvement [11]. Together, they can make a great combination for improving the quality of IT services [11]. 
TABLE. I. The NinE ElEMENTS OF IT GOVERNANCE [21]

\begin{tabular}{|l|l|}
\hline IT Governance Practice & Supporting Literature \\
\hline Business Strategic Planning: capturing and synthesizing how the organization can reach its vision. & {$[30]$} \\
\hline IT Strategic Planning: conceptualizing and assimilating how the organization can meet its vision by leveraging IT. & {$[31,32,33,34]$} \\
\hline $\begin{array}{l}\text { IT Organizational Structure: the way the IT function is structured (e.g., centralized, decentralized, federated) and where the IT } \\
\text { decision-making authority is located within the organization. }\end{array}$ & {$[35,36]$} \\
\hline IT Reporting: who manages the senior IT executive and IT function; and how. & {$[37,38]$} \\
\hline $\begin{array}{l}\text { IT Budgeting: financial control (processes for allocating financial resources; is IT managed as a cost center, investment center, } \\
\text { profit center, etc.) }\end{array}$ & {$[39,40]$} \\
\hline $\begin{array}{l}\text { IT Investment Decisions: how IT asset spending is allocated and reviewed (e.g., cost-based, creating business value, etc.), and by } \\
\text { whom. }\end{array}$ & {$[41,42]$} \\
\hline $\begin{array}{l}\text { IT Steering Committee(s): strategic, tactical, and operational teams commissioned to allocate and oversee IT initiatives, priorities, } \\
\text { spending, and resource allocation. }\end{array}$ & {$[43,44,45]$} \\
\hline IT project prioritization process: how IT projects are selected, and by whom. & {$[46,47]$} \\
\hline IT Reaction Capability: IT's ability to quickly respond to the organization's changing business needs/demands & {$[48,49]$} \\
\hline
\end{tabular}

Based on previous studies, none of these frameworks can provide an integrated work, and they cited that to cover and treat all IT organizations' concerns, it is necessary to choose a good combination of these frameworks. To adopt IT Governance, organizations are being forced to adopt and integrate multiple IT standards and frameworks to comply with the increasing demands of the industry coupled with compliance requirements [26] but struggle with the complexity and difficulty of understanding and adopting several practices at the same time [27]. The integration of IT standards and best practices has many benefits. The primary one is the enabling of features that would be unavailable through the use of practices individually, leading to a more comprehensive and efficient approach [28, 29]. Hence the need for an integrated solution to consolidate the best combination of IT standards and their best practices. In order to create a digital strategy approach that is based on IT governance and take advantage of its components, IMFDS framework will be articulated across IT Governance components (Table I) [21]: Business Strategic Planning, IT Strategic Planning, IT Organizational Structure, IT Reporting, IT Budgeting, IT Investment Decisions, Steering committee, IT Prioritization Process and IT Reaction Capacity.

\section{IT Frameworks Structure}

A literature review has been conducted on the most wellknown IT Frameworks in the literature (COBIT, ITIL, BSC, CMMI, and EFQM) and their structure in order to provide a standard and known framework by practitioners. Meta-Models of these frameworks have been studied in order to define the structure and the most common elements between them. Metamodels allow the analysis and presentation of existing concepts of a model and how these concepts relate to each other, giving an idea of how the model works [50]. Meta-models allow reducing the perceived complexity of IT frameworks by representing their concepts and relationships with graphical concepts. Meta-models facilitate the learning of IT standards (reduce the perceived complexity), as well as understand their main components and their relationships. Several works have studied and developed meta-models of the well-known IT frameworks and have proposed some integration between these models: ITIL Meta-Model [23], COBIT Meta-Model [51, 52],
ITIL and COBIT Meta-Models integration [23], CMMI Metamodel [50], ISO 27001 Metamodels [53].

Based on this review, it has been deduced that the common structural elements between these frameworks are that they give a toolbox to solve a specific problem or several problems in the information system of the organization. This toolbox contains processes, best practices, criteria, goals, activities, and metrics. To maintain the same structure that is standard and known by practitioners, the IMFDS framework is also designed as a toolbox that contains processes, goals, good practices, and metrics to guarantee a successful digital transformation.

\section{PROPOSED SOLUTION: IMFDS FRAMEWORK DESCRIPTION}

This section describes the components and structure of the suggested methodological framework IMFDS.

IMFDS framework provides an approach to guide the implementation of an efficient digital transformation in different organizations. It is composed of two systems as illustrated in Fig. 1. The first system is dedicated to define the strategic plan for the digital transformation while the second one is dedicated on the one hand to assessing and monitoring the progress of the implementation of the digital strategy, and on the other hand to continually improve the digital strategy and its components. The following figure (Fig. 1) provides an overview of the systems and the key components involved by the proposed framework in the process of establishing a digital strategic planning.

\section{A. IMFDS Components}

The following figure (Fig. 2) shows the complete set of processes within the IMFDS framework (34 processes).

1) Digital strategy building system: The Digital Strategy Building System of the IMFDS framework is articulated across the following blocks: Business Strategic Planning, IT Strategic Planning, IT Organizational Structure, IT Reporting, IT Budgeting, IT Investment Decisions, Steering committee, IT Prioritization Process and IT Reaction Capacity. To build a 
digital transformation strategy, organizations should follow these guidelines:

\section{Step 1 - Build the Business Strategic Planning}

The business strategic planning is composed of a strategic vision and an action plan to reach this vision.

- Strategic Vision: The first challenge of a digital transformation is to develop the strategic vision in which you determine why the organization needs a digital transformation, what are strategic goals, changes, and desired outcomes of this transformation, and what are resources required to perform the digital transformation.

- Action Plan: An action plan is a set of planned projects, programs, activities, and resources to reach the strategic vision.

\section{Step 2 - Define the IT Organizational Structure}

To define the IT organizational structure organizations should determine how people work together in the IT department to create value and benefits. The IT organizational structure should facilitate company growth, increases profits, and optimizes internal operations. To build such a good IT Organizational structure, organizations determine the following elements:
- Critical problems that should be solved by the IT department.

- The conception of an optimal combination of Internal IT Department Vs Outsourced IT staff who will contribute to the digital transformation.

- Flexible IT Department Structure that can be Adapted easily.

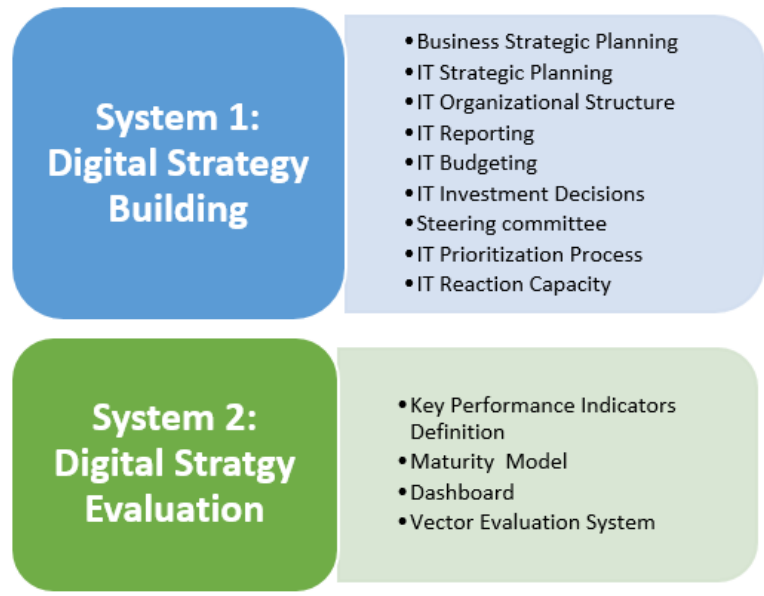

Fig. 1. IMFDS Components.

- Required skills in the IT department for digital transformation [54].

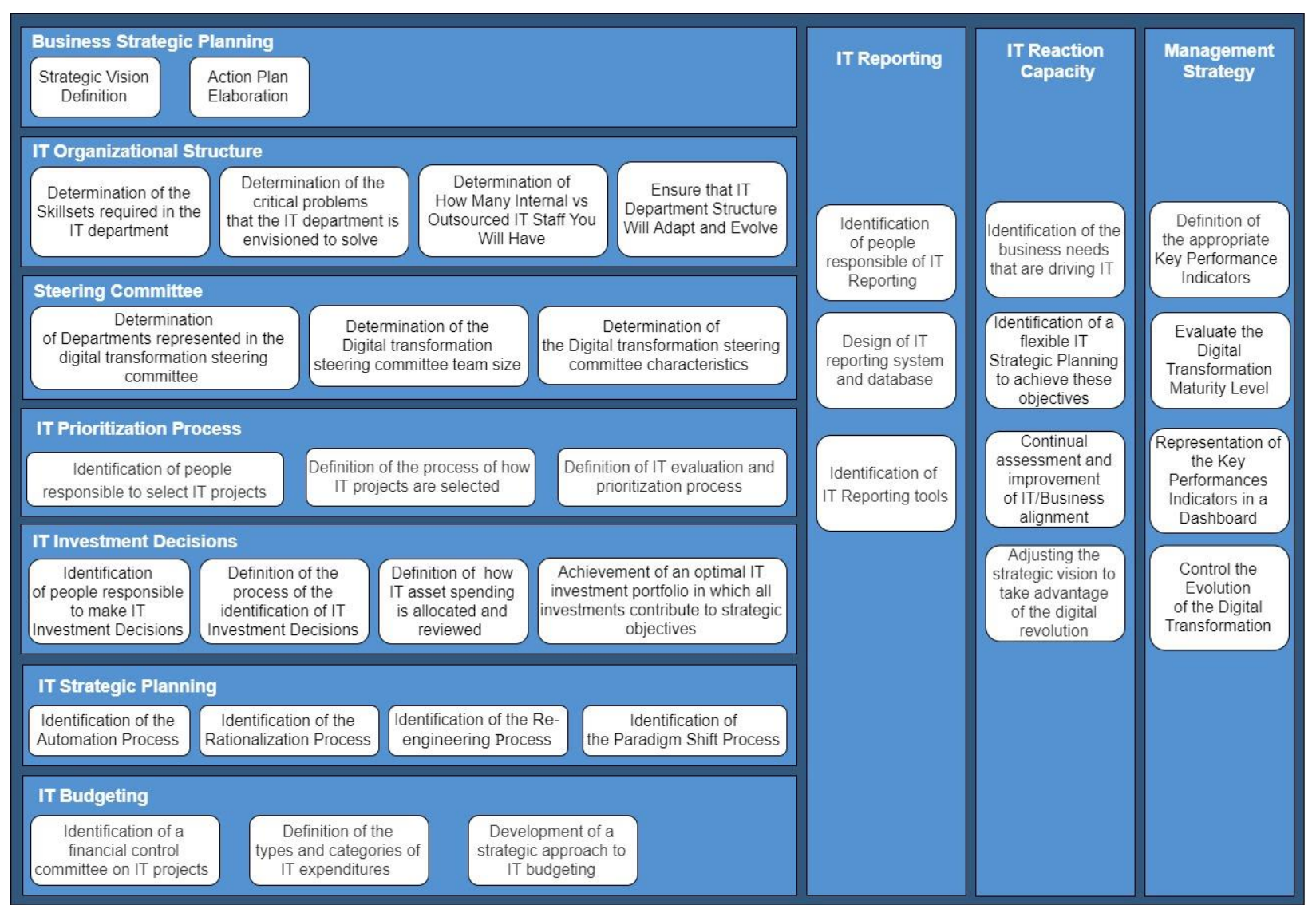

Fig. 2. IMFDS Processes (34 Processes). 


\section{Step 3 - Build the Steering committee}

A steering committee is composed of strategic, tactical, and operational teams commissioned to allocate and oversee IT initiatives, priorities, spending, and resource allocation [21]. Steering committees include cross-functional and interdepartmental members and are essential to driving meaningful change across the enterprise [14]. In order to build the steering committee company executives should determine:

- Departments represented in the digital transformation steering committee (ex: IT, customer service, marketing, innovation, e-commerce, human resources, employee engagement, $\mathrm{R} \& \mathrm{D}$, product groups).

- Digital transformation steering committee team size.

- Digital transformation steering committee characteristics (Formal or Informal Committee)

Step 4 - Define the IT Prioritization Process

It is a process of management of the portfolio of IT projects. This process defines how IT projects are selected and identify people responsible to select IT projects. The process defines also the priorities of IT projects [9]. For evaluating and prioritizing projects, organizations should:

- Identify people responsible to select IT projects.

- Identify the process of how IT projects are selected (Identify project drivers).

- Identify the process of how IT projects are evaluated and prioritized. Once you have gathered the list of IT projects, AHP (Analytic Hierarchy Process) [55] Model can be adopted in order to priorities IT projects based on the creation of an evaluation and prioritization matrix.

Step 5 - Define How IT Investment Decisions are made and How made them.

Define How IT asset spending is allocated and reviewed (e.g., cost-based, creating business value, etc.), and identify people responsible to do this study [21]. A decision is made in a process that follows two stages, the first of which is the formulation of the decision, in which the decision is prepared and ends with the specific commitment to action; in the second stage, the decision is implemented [56]. Compared with other types of decisions, IT investment decisions have some specific Characteristics [56]:

- IT investments require funds or budgets.

- IT investment decisions cannot be taken in isolation.

- Achievement of an optimal IT investment portfolio in which all investments contribute to strategic objectives.

- IT investment decisions should follow the two stages of decision-making: the formulation and the implementation stage.

Step 6 - Build IT Strategic Planning

IT strategic planning and business strategic planning complement each other to achieve the strategic vision. The IT Strategic Planning should define how new technologies can achieve the organization's vision, improve its business process, impel the competitiveness and improve its smartness [9]. It should highlight the four types of organizational change enabled by IT namely, automation, rationalization, reengineering and paradigm shift [9]:

- Automation: refers to the application of IT to assist employees in performing their jobs more efficiently and to speed up the performance of existing tasks.

- Rationalization of procedures: streamlining of standard operating procedures, eliminating bottlenecks so that automation makes the procedures more efficient.

- Reengineering: refers to the radical redesign of business processes with the goal of reducing significantly the costs of business and take advantage of IT.

- Paradigm shift: a more radical form of reengineering, involves the radical reconceptualization of the nature of the business and the nature of the organization.

Step 7 - Define How IT Budgeting is Managed

Organizations struggle with IT budgeting. To manage IT projects funding it is necessary to:

- Identify a financial control committee on IT projects [9].

- Define the types and categories of IT expenditure.

- Develop a strategic approach to IT budgeting [57].

Step 8 - Define the IT Reporting System

The reporting function is more than preparing an annual report, quoting statistics, and informing your staff of current developments [58]. The reporting function compares how you are doing with what you set out to do. IT Reporting allows Identifying who manages the senior IT executive and IT function; and how [21]. IT reporting should focus on the things that quantify the value that IT delivers to the organization. It should illustrate the percentage of successful change implementations that have been triggered using IT. To perform a good IT Reporting, organizations should:

- Identify people responsible for managing and monitoring IT function, IT objectives and IT results.

- Identify the conception of characteristics, data, and measures that should be included in IT Reports.

- Identify IT reporting tools that will be used by the organization.

Step 9 - Define the IT Reaction Capacity Process

Organizations should study, measure and evaluate the ability of IT to be aligned easily to any change in the business process of the organization and to respond quickly to new demands [9]. IT managers deal with external environmental changes, changing internal customer needs, and rapid technology changes [49]. Studies suggest that to manage change and prepare for uncertainty, IT leaders should create an organization that is more flexible [49]. The alignment between Business and IT requires the definition of a process. This 
process should be based on anticipation, agility, and adaptability [49]. The main steps that must be included in this process are:

- Identification of the strategic objectives that are driving the digital transformation (Strategic Vision).

- Identification of a flexible IT Strategic Planning to achieve these objectives.

- Continual assessment and improvement of IT/Business alignment.

- Adjusting the strategic vision to take advantage of the digital revolution.

2) Digital strategy evaluation system: The Digital Strategy Evaluation System of the proposed framework is a system designed to help the organization establishing a Management Strategy to manage the digital transformation strategy. A strategy is a continual process that needs management and monitoring. To monitor the digital transformation strategy, organizations need a management strategy. KPIs are useful tools for efficiently monitoring the digital transformation strategy. In this regard, an appropriate set of relevant indicators must be established and properly evaluated [16]. A management strategy should define a list of indicators that include the perspective of stakeholders and allow to monitor the digital strategy progress, assess the digital strategy results, make appropriate decisions [16]. The Digital Strategy Evaluation System of the proposed framework helps the organization to:

- Define Key Performance Indicators: by implementing the Goal Question Metric Method. Goal Question Metric (GQM) is a suitable approach to define relevant KPIs [16]. It is a well-known paradigm proposed by Basili for defining the software measurements [59]. The GQM approach identifies three steps, it provides a method for defining Goals, refining them into Questions and then defining the Metrics to collect data. This approach has been applied successfully in several contexts [16] and it will be successful also in the context of this work. GQM defines a top-down approach based on three levels: a conceptual level (Goal); an operational level (Question); and a quantitative level (Metric). This method will help to exploit KPIs for assessing strategic goals.

- Evaluate the Digital Transformation Maturity Level: IMFDS framework integrates MMDSA (The Maturity Model for Digital Strategy Assessment) Model. MMDSA is a maturity model for monitoring the digital strategy progress, evaluating the alignment between the business strategy and the digital strategy, and assessing the benefits of IT projects [9].

- Represent the Key Performances Indicators in a Dashboard: dashboards allow quick access to key performance indicators via data visualizations and simple metrics.
- Control the Evolution of the Digital Transformation: to evaluate the progress of the digital strategy and control the achievement of the strategic goals, Key Performance Indicators will be used. These KPIs will allow assessing and monitoring the achievement of the associated strategic goal using Control Theory in order to control the variation and development of KPIs measurements at any moment of time [16]. The control theory studies the possibility of acting on a dynamical system dependent on the temporal variable in order to lead the state of this system to a given state at a given instant. The dynamical system in this work is RSgObj vector, it is the ranking vector of KPIs, it provides a clear idea of the reality of achievement of the strategic goals at a given moment in time.

$$
\left(\begin{array}{l}
\mathrm{R}_{\text {Sgobjl }}\left(\mathrm{t}_{0}\right) \\
\mathrm{R}_{\text {Sgobj2 }}\left(\mathrm{t}_{0}\right) \\
\vdots \\
\mathrm{R}_{\text {SgObjn }}\left(\mathrm{t}_{0}\right)
\end{array}\right) \Rightarrow\left(\begin{array}{l}
\mathrm{R}_{\text {SgObjl }}(\mathrm{t}) \\
\mathrm{R}_{\text {SgObj2 }}(\mathrm{t}) \\
\vdots \\
\mathrm{R}_{\text {SgObjn }}(\mathrm{t})
\end{array}\right) \leadsto\left(\begin{array}{l}
\mathrm{R}_{\text {SgObjl }}\left(\mathrm{t}_{1}\right) \\
\mathrm{R}_{\text {SgObj2 }}\left(\mathrm{t}_{1}\right) \\
\vdots \\
\mathrm{R}_{\text {SgObjn }}\left(\mathrm{t}_{1}\right)
\end{array}\right)
$$

AsIs

ToBe

$\mathbf{R}_{\mathrm{SgObji}}=\sum_{\mathbf{j}=\mathbf{1}}^{\mathbf{m}}(\mathbf{V j} * \mathbf{W} \mathbf{j}):$ Rank of KPIs associated to the strategic goal $i$.

n: Number of strategic goals.

$\boldsymbol{m}$ : Number of KPIs associated to the strategic goal $i$.

t0: The initial moment.

t1: Moment of reaching objective values of KPIs.

\section{B. IMFDS Structure}

IMFDS framework is designed as a toolbox that contains processes, goals, good practices, and metrics (Fig. 3). The following figure (Fig. 3) illustrates the meta-model of IMFDS framework (this meta-model is designed using ArchiMate [60]). The core elements of this framework are processes. A process can be seen as the glue that connects people, tools and equipment, and procedures and methods in a consistent way through a set of interrelated activities that, together, interact to achieve objectives. An objective is controlled by metrics.

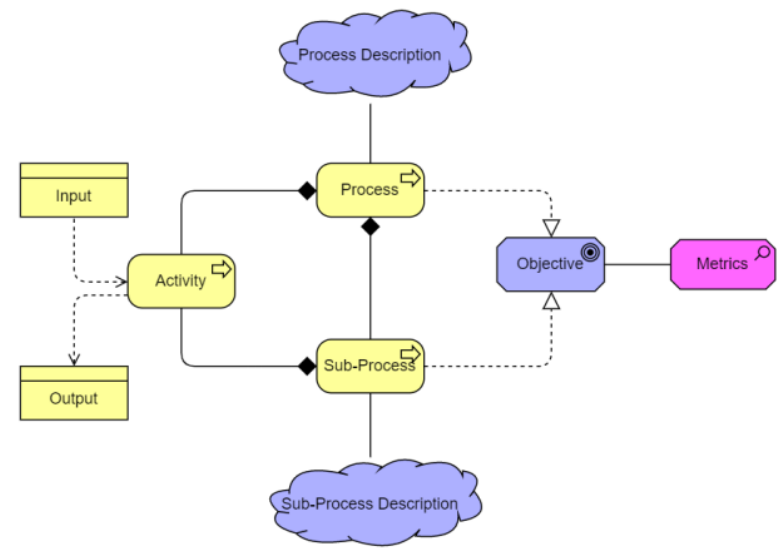

Fig. 3. IMFDS META-Model. 
TABLE. II. IMFDS AND ARCHIMATE ONTOLOGICAL MAPPING

\begin{tabular}{|c|c|c|c|c|}
\hline $\begin{array}{l}\text { IMFDS } \\
\text { Concept }\end{array}$ & IMFDS Concept Description & $\begin{array}{l}\text { Archi-Mate } \\
\text { Notation }\end{array}$ & ArchiMate Concept Description [61] & $\begin{array}{l}\text { Archi-Mate } \\
\text { Representation }\end{array}$ \\
\hline Process & $\begin{array}{l}\text { Set of interrelated activities and sub- } \\
\text { processes which generate an objective }\end{array}$ & $\begin{array}{l}\text { Business } \\
\text { Process }\end{array}$ & $\begin{array}{l}\text { Behavior element that groups behavior based on } \\
\text { an ordering of activities }\end{array}$ & Process $\Rightarrow$ \\
\hline Sub-Process & $\begin{array}{l}\text { Set of interrelated activities and sub- } \\
\text { processes which achieve a goal }\end{array}$ & $\begin{array}{l}\text { Business } \\
\text { Process }\end{array}$ & $\begin{array}{l}\text { Behavior element that groups behavior based on } \\
\text { an ordering of activities }\end{array}$ & Sub-Pro \\
\hline Objective & $\begin{array}{l}\text { An objective is the output of a process or a } \\
\text { sub-process }\end{array}$ & Goal & $\begin{array}{l}\text { An end state that a stakeholder intends to } \\
\text { achieve. }\end{array}$ & objective (9) \\
\hline Metrics & $\begin{array}{l}\text { Metrics are used to control the achievement } \\
\text { of objectives }\end{array}$ & Assessment & The outcome of some analysis of some drivers. & Metrics \\
\hline Composition & Composition & Composition & Composition & \\
\hline Realization & Realization & Realization & Realization & \\
\hline Description & Process description & Meaning & $\begin{array}{l}\text { The knowledge or expertise present in a } \\
\text { business object or its representation, given a } \\
\text { context. }\end{array}$ & \\
\hline Activity & $\begin{array}{l}\text { A set of actions designed to consumes inputs } \\
\text { and generates outputs within a period time }\end{array}$ & $\begin{array}{l}\text { Business } \\
\text { Process }\end{array}$ & $\begin{array}{l}\text { Behavior element that groups behavior based on } \\
\text { an ordering of activities }\end{array}$ & Activity $\Rightarrow$ \\
\hline Input & An activity consumes inputs & Business Object & $\begin{array}{l}\text { A passive element that has relevance from a } \\
\text { business perspective. }\end{array}$ & Input \\
\hline Output & An activity consumes outputs & Business Object & $\begin{array}{l}\text { A passive element that has relevance from a } \\
\text { business perspective. }\end{array}$ & Output \\
\hline $\begin{array}{l}\text { Consume } \\
\text { /Generate }\end{array}$ & $\begin{array}{l}\text { Representation of consummation and } \\
\text { generation relations }\end{array}$ & Influence & Influence & $-\cdots-\cdots-y$ \\
\hline
\end{tabular}

Table II illustrates the description of IMFDS METAMODEL components and their mapping with ArchiMate ontological.

\section{DISCUSSION}

Several works have studied the concepts, concerns, and strategies of the digital transformation. However, specific guidelines for organizations on how to build and monitor digital transformation strategies are still not clear. The purpose of the paper is to propose a framework of digital transformation strategy building using IT governance components as constructed blocks of the proposed framework. The suggested framework provides specific guidelines on how to build and monitor a digital transformation strategy. To build an integrative and user-friendly framework, a literature review has been conducted about IT governance and about the structures, components, and limitations of the well-known IT frameworks (COBIT5, ITIL4, CMMI-DEV, BSC, and EFQM). Based on this review, the structure and the core components of IMFDS framework have been defined as follows: Processes, Activities, Input/Output, Goals, and Key Performance indicators. IMFDS framework is based on IT governance elements, and its processes will take advantage of the processes, and limitations of the following frameworks: COBIT5, ITIL4, CMMI-DEV, BSC, and EFQM.

\section{CONCLUSION}

This research was developed with the purpose of taking advantage of IT governance components for developing a digital transformation framework to help originations building and monitoring the digital transformation strategy. The proposed framework is composed of two systems. The first one is a Digital Strategy Building System; it provides nine steps for building the digital transformation strategy. The second one is a Digital Strategy Evaluation System, it allows defining key performance indicators, evaluating the digital transformation maturity level, representing the key performance indicators in a dashboard, and controlling the evolution of the digital transformation. This paper presents the different blocks and processes of IMFDS framework. The following promising future directions of the current work can be considered in future research:

- IMFDS framework is based on IT governance only and this can be a limitation. Future research should also consider additional digital strategy concepts and dimensions as the basis of digital transformation strategies.

- Analysis of the individual IT Governance elements impact on the digital strategy.

- Design and definition of the processes, objectives, metrics, and activities of IMFDS framework (analysis and comparison of the proposed approach with some well-known frameworks like COBIT, ITIL, CMMIDEV, BSC, and EFQM to take advantage of their best practices).

\section{REFERENCES}

[1] Hess, T., Matt, C., Benlian, A., Wiesböck, F. (2016). Options for Formulating a Digital Transformation Strategy. June 2016 (15:2)| MIS Quarterly Executive.

[2] Mitroulis D., Kitsios F. (2019). Digital Transformation Strategy: A Literature Review. Department of Applied Informatics University of

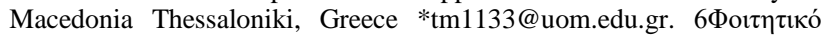

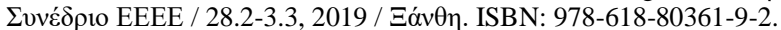


[3] Vial, G., (2019). Understanding digital transformation: A review and a research agenda. Journal of Strategic Information Systems, https://doi.org/10.1016/j.jsis.2019.01.003.

[4] Zinder, E., Yunatova, I. (2016). Synergy for digital transformation: person's multiple roles and subject domains integration. In: Digital Transformation and Global Society, pp. 155-168 (2016).

[5] Mario Spremic. (2017). Governing digital technology - how mature IT governance can help in digital transformation? International Journal of Economics and Management Systems. http://www.iaras.org/iaras/ journals/ijems. Volume 2, 2017. ISSN: 2367-8925.

[6] De Haes, S., Caluwe, L., Huygh, T., \& Joshi, A. (2020). Governing Digital Transformation. Management for Professionals. doi:10.1007/978-3-030-30267-2.

[7] Westerman, G., Bonnet, D., McAfee, A., (2014). The nine elements of digital transformation. 7,from https://sloanreview.mit.edu/article/thenine-elements-of-digitaltransformation/.

[8] Westerman,G., Calméjane, C., Bonnet, D., Ferraris, P., McAfee, A. (2011). Digital transformation: a roadmap for billion-dollar organizations. In: MIT Center for Digital Business and Capgemini Consulting, pp. 1-68.

[9] Korachi, Z. and Bounabat, B. (2019a). Towards a Maturity Model for Digital Strategy Assessment. Second Edition of the International Conference On Advanced Intelligent Systems for Sustainable Development Applied To Agriculture, Energy, Health, Environment Industry and Economy. VOLUME 4 (ISBN 978-3-030-3667-35): Advanced Intelligent Systems for applied Computing Sciences. AI2SD, 08-11 July 2019, Marrakech, Morocco.

[10] Christine, M., and Megan, H. (2018). Digital Strategy Environmental Scan for the Concordia University Digital Strategy Committee. Athenaeum21 Consulting for Concordia University, (C) June 2018. https: //www.concordia.ca/content/dam/concordia/docs/strategic-directions/ Concordia-University-Digital-Strategy-Environmental-Scan.pdf.

[11] Peña, S., José, J., Vicente, F., E., Ocaña, M., A. (2013). ITIL, COBIT and EFQM: Can They Work Together? International Journal of Combinatorial Optimization Problems and Informatics. IJCOPI Vol. 4, No. 1, Jan-April 2013, pp. 54-64. EDITADA. ISSN: 2007-1558.

[12] Long, J. O. (2012). ITIL® 2011 At a Glance. SpringerBriefs in Computer Science. doi:10.1007/978-1-4614-3897-7.

[13] Ayyagari, M. and Atoum I. (2019). CMMI-DEV Implementation Simplified. International Journal of Advanced Computer Science and Applications. 2019;10(4). doi:10.14569/ijacsa.2019.0100455.

[14] Solis, B. (2019). The state of digital transformation. 2018-2019 edition. by brian solis, principal analyst. Altimeter Report.

[15] World Health Organization and International Telecommunication Union. (2012). National eHealth Strategy Toolkit.

[16] Korachi, Z. and Bounabat, B. (2019b). Integrated Methodological Framework for Smart City Development. ISBN: 978-989-8533-90-6 () 2019. International Conferences ICT, Society, and Human Beings 2019; Connected Smart Cities 2019; and Web Based Communities and Social Media 2019, Porto, Portugal.

[17] Korachi, Z. and Bounabat, B. (2019c). Towards a Platform for Defining and Evaluating Digital Strategies for Building Smart Cities. IEEE ISBN: 978-1-7281-3848-0. The 3rd. International Conference on Smart Grid and Smart Cities (ICSGSC 2019), University of California, Berkley, USA, June 25-28, 2019.

[18] Kamariotou M., Kitsios F. (2017). Department of Applied Informatics University of Macedonia Thessaloniki, Strategic Information Systems Planning: Implementing a Digital Strategy. DOI: 10.4018/978-1-52252255-3.ch078. In book: Encyclopedia of Information Science and TechnologyEdition: Fourth EditionChapter: 78Publisher: IGI Global PublishingEditors: Mehdi Khosrow-Pour.

[19] Boström, E., Can Celik, O. (September 2017). Towards a Maturity Model for Digital Strategizing A qualitative study of how an organization can analyze and assess their digital business strategy.

[20] Korachi, Z. and Bounabat, B. (2018). Data Driven Maturity Model for Assessing Smart Cities. ICSDE'18, October 18- 20, 2018, Rabat, Morocco; () 2018 Association for Computing Machinery; ACM ISBN 978-1-4503-6507-9/18/10; ENSIAS Rabat; Morocco.
[21] Luftman, J., Ben-Zvi, T., Dwivedi, R., \& Rigoni, E. H. (2010). IT Governance. International Journal of IT/Business Alignment and Governance, 1(2), 13-25. doi:10.4018/jitbag.2010040102.

[22] Maqbool, M. H. (2015). A consolidated model for putting Balanced Scorecard into action in Pakistan's textile industry. Journal of Strategy and Performance Management, 3(1), 40-46.

[23] Percheiro, I., Almeida, R., Pinto, P. L., \& da Silva, M. M. (2017). Towards Conceptual Meta-Modeling of ITIL and COBIT 5. Lecture Notes in Business Information Processing, 478-491. doi:10.1007/978-3319-65930-5_38.

[24] Gehrmann, M. (2012). Combining ITIL COBIT and ISO/IEC 27002 for structuring comprehensive information technology for management in organizations. Navus-Rev. Gest ao Tecnol.2(2), 66-77 (2012).

[25] Michalska, J. (2008) Using the EFQM excellence model to the process assessment, Vol . 27, No. 2. Journal of Achievements in Materials and Manufacturing Engineering, 2008.

[26] Looso, S., Goeken, M. (2010). Application of best-practice reference models of IT governance. In: ECIS (Paper 129).

[27] Pardo, C., Pino, F.J., Garc'1a, F., Piattini, M., Baldassarre, M.T. (2012). An ontology for the hamonization of multiple standards and models. Comput. Stand. Interfaces34, 48-59.

[28] Cater-Steel, A., Tan, W.G., Toleman, M. (2006). Challenges of adopting multiple process improvement frameworks. In: 14th European Conference on Information Systems (ECIS).

[29] Ula, M., Ismail, Z., Sidek, Z.M. (2011). A framework for the governance of information security in banking system. J. Inf. Assur. Cyber Secur.2011, 1-12.

[30] Mintzberg, H., Ahlstrand, B., \& Lampel, J. (2000). Safari de estratégia. Porto Alegre, Brazil: Bookman.

[31] Peterson, R. (2004). Crafting information technology governance. Information Systems Management, 21(4), 7-22. doi:10.1201/1078 /44705.21.4.200409 01/84183.2.

[32] Lee, G., \& Bai, R. (2003). Organizational mechanisms for successful is/it strategic planning in the digital era. Management Decision, 41(1), 32-42. doi:10.1108/00251740310445536.

[33] Jiang, J., \& Klein, G. (1999). Project selection criteria by strategic orientation. Information \& Management, 36(2), 63-75. doi:10.1016/S0378-7206(99)00009-9.

[34] Teo, T., \& King, W. (1997). Integration between business planning and information systems planning: an evolutionary-contingency perspective. Journal of Management Information Systems, 14(1), 185-214.

[35] Sambamurthy, V., \& Zmud, R. (1999). Arrangements for Information Technology Governance: A Theory of Multiple Contingencies. Management Information Systems Quarterly, 23(2), 261-290. doi:10.2307/249754.

[36] Brown, C., \& Magill, S. (1994). Alignment of the IS Functions with the Enterprise: Toward a Model of Antecedents. Management Information Systems Quarterly, 18(4), 371-403. doi:10.2307/249521.

[37] Raghunathan, T. (1992). Impact of the CEO's participation on information systems steering committees. Journal of Management Information Systems, 8(4), 83-96.

[38] Smaczny, T. (2001). Is an alignment between business and information technology the appropriate paradigm to manage IT in today's organisations. Management Decision, 39(10), 797-802. doi:10.1108/ EUM0000000006521.

[39] Venkatraman, N. (1997). Beyond Outsourcing: Managing IT Resources as a Value Center. Sloan Management Review, 38(3), 51-64.

[40] Jensen, M., \& Meckling, W. (1998). Divisional performance measurement . In Foundations of Organizational Strategy. Cambridge, MA: Harvard University Press.

[41] Gunasekaran, A., Love, P., Rahimi, F., \& Miele, R. (2001). A model for investment justification in information technology projects. International Journal of Information Management, 21, 349-364. doi:10.1016/S02684012(01)00024-X.

[42] Boonstra, A. (2003). Structure and analysis of IS decision-making processes. European Journal of Information Systems, 12(3), 195-209. doi:10.1057/ palgrave.ejis.3000461. 
[43] Weill, P., \& Ross, J. (2004). IT Governance - How Top Performers Manage IT Decision Rights for Superior Results. Boston, MA: Harvard Business School Press.

[44] Mintzberg, H. (2003). Criando organizações eficazes: estruturas em cinco configurações. Porto Alegre, Brazil: Atlas.

[45] Karimi, J. (2000). The Effects of MIS Steering Committees on Information Technology Management Sophistication. Journal of Management Information Systems, 17(2), 207-230.

[46] Wu, L., \& Ong, C. (2008). Management of information technology investment: A framework based on a Real Options and Mean-Variance theory perspective. Technovation, 28(3), 122-134. doi:10.1016/j. technovation.2007.05.011.

[47] Wen, H., \& Shih, S. (2006). Strategic Information Technology Prioritization. Journal of Computer Information Systems, 46(4), 54-63.

[48] Schildt, K., Beaumaster, S., \& Bailey, S. (2006). Organization Antecedents of Successful IT Management. In Proceedings of the 39th Annual Hawaii International Conference on System Sciences.

[49] Patten, K., Whitworth, B., Fjermestad, J., \& Mahinda, E. (2005) Leading IT Flexibility: Anticipation, Agility and Adaptability. In Proceedings of 11th Americas Conference on Information Systems Engineering.

[50] Valverde, L., Mira da Silva, M., \& Gonçalves, M. R. (2018). CMMIDEV v1.3 Reference Model in ArchiMate. On the Move to Meaningful Internet Systems. OTM 2018 Conferences, 191-208. doi:10.1007/978-3030-02671-4_11.

[51] Almeida, R., Pinto, P.L., da Silva, M.M. (2016). Using ArchiMate to integrate COBIT and COSO metamodels. In: European, Mediterranean and Middle Eastern Conference on Information Systems, Krakow, Poland, p. 5.

[52] Souza Neto J and Ferreira Neto A. (2013). Metamodel of the IT Governance Framework COBIT. Journal of Information Systems and Technology Management. 2013;10(3):521-540. doi:10.4301/s180717752013000300004
[53] Lourinho, R., Almeida, R., Mira da Silva, M., Pinto, P., \& Barafort, B. (2017). Mapping of Enterprise Governance of IT Practices Metamodels. Lecture Notes in Business Information Processing, 492-505. doi:10.1007/978-3-319-65930-5_39.

[54] Sousa, M. J., \& Rocha, Á. (2018). Digital learning: Developing skills for digital transformation of organizations. Future Generation Computer Systems. doi:10.1016/j.future.2018.08.048.

[55] Teknomo, K. (2006). Analytic hierarchy process (AHP) tutorial. Revoledu. com. Available at: https://people.revoledu.com/kardi/ tutorial/AHP/. Accessed September 23, 2019.

[56] Van den Berg, M., Slot, R., van Steenbergen, M., Faasse P, van Vliet H. (2019). How enterprise architecture improves the quality of IT investment decisions. Journal of Systems and Software. 2019;152:134150. doi:10.1016/j.jss.2019.02.053.

[57] Hu, Q., \& Quan, J. (2006). The Institutionalization of IT Budgeting. Information Resources Management Journal, 19(1), 84-97. doi:10.4018/irmj.2006010105.

[58] Waldron, M., W., Vsanthakumar, J., and Arulraj, S. (1998). Chapter 13 Improving the organization and management of extension. Improving agricultural extension. A reference manual. ISBN 92-5-104007-9.

[59] Basili, V. R. (1993). Applying the Goal/Question/Metric paradigm in the experience factory (pp. 21-44). Software Quality Assurance and Measurement: A Worldwide Perspective.

[60] Desfray, P., and Raymond, G. (2014). ArchiMate. Modeling Enterprise Architecture with TOGAF, 249-258.doi:10.1016/b978-0-12-4199842.00014-8

[61] The Open Group. (2013). ArchiMate ${ }^{\circledR} 2.1$ Specification. Pubs.opengroup.org. https://pubs.opengroup.org/architecture/archimate2 -doc/. Published 2012- 2013. Accessed September 23, 2019. 